Kansas State University Libraries

New Prairie Press

\title{
SPECTRAL PROCEDURES ENHANCE THE ANALYSIS OF THREE AGRICULTURAL TIME SERIES
}

D. Meek

J. Prueger

M. Tomer

R. Malone

See next page for additional authors

Follow this and additional works at: https://newprairiepress.org/agstatconference

Part of the Agriculture Commons, and the Applied Statistics Commons

\section{(c) (1) $\Theta(9$}

This work is licensed under a Creative Commons Attribution-Noncommercial-No Derivative Works 4.0 License.

\section{Recommended Citation}

Meek, D.; Prueger, J.; Tomer, M.; and Malone, R. (2007). "SPECTRAL PROCEDURES ENHANCE THE ANALYSIS OF THREE AGRICULTURAL TIME SERIES," Conference on Applied Statistics in Agriculture. https://doi.org/10.4148/2475-7772.1115

This is brought to you for free and open access by the Conferences at New Prairie Press. It has been accepted for inclusion in Conference on Applied Statistics in Agriculture by an authorized administrator of New Prairie Press. For more information, please contact cads@k-state.edu. 
Author Information

D. Meek, J. Prueger, M. Tomer, and R. Malone

This is available at New Prairie Press: https://newprairiepress.org/agstatconference/2007/proceedings/12 


\title{
SPECTRAL PROCEDURES ENHANCE THE ANALYSIS OF THREE AGRICULTURAL TIME SERIES
}

\author{
D. Meek, J. Prueger, M. Tomer, and R. Malone \\ USDA-ARS-MWA National Soil Tilth Laboratory \\ Ames, IA 50011-4420 USA
}

\begin{abstract}
Many agricultural and environmental variables are influenced by cyclic processes that occur naturally. Consequently their time series often have cyclic behavior. This study develops time series models for three different phenomena: (1) a 60 year-long state annual average crop yield record, (2) a four year-long daily stream flow record with values aggregated to weekly averages, and (3) a half-hour long wind speed record sampled at 10 hertz with values aggregated to $0.5 \mathrm{~min}$ averages. Trend tests, simple high pass filtering, and spectral analysis on original and detrended and residual data series are used to guide model development. Next, as a means to provide insight for researchers, nonlinear regression procedures are used to develop models in the time domain. The models considered may have a large scale trend, low to high frequency cycles, and, if need be, an autoregressive (AR) error structure. Selected models for all three sets included a trend component. The model for yield has a linear trend in time and includes two high frequency cycles of 2.3 and 2.5 years. The model for stream flow has a complicated trend consisting of splined polynomials in the square root of time. Cycles include an annual and approximately 8,6 , and 3 month periods. Also an AR1 error structure is added. Results suggest the wind speed can be modeled as a superposition of damped and undamped oscillations. A zero order fractional Bessel function models the trend, here a damped oscillation with a period of $10.5 \mathrm{~min}$. Smaller scale regular cycles of 6.6, 3.3 and 2.2 min are added along with an AR1 error structure. The use of time series methods instead of the inverse transform on selected frequencies allows for simultaneous estimation of all components. Moreover it opens the door to the use of a much broader class of functions to model the trend, to the use of other kinds of periodic functions to model the cycles, and to the incorporation of structure in the error term. This approach may provide useful insight and a methodological approach for several ongoing and some future studies at the National Soil Tilth Laboratory.
\end{abstract}

Key Words: Fourier Analysis, Discrete Fourier Transform, Stationary Series, Spectral Density, Periodgram, Autocorrelaton, and Robust Procedure. 


\section{INTRODUCTION}

Environmental processes can produce cyclic behavior in the observational record for many different phenomena and time scales of interest. Among these natural phenomenon are wellknow climatic oscillations like the El Niño-Southern Oscillation (ENSO), the Quasi-Biennial Oscillation (QBO), and the North-Atlantic Oscillation (NAO). These cycles effect atmospheric conditions, seasonal weather patterns, and hence, consequent agricultural hydrology and crop development. The determination of long-term, annual cycles, and sub-annual cycles in a hydrological time series has become an import initial analysis step and a prelude to further analyses (Tomer et al., 2003 and Tomer et al., 2005). In records from some Midwestern crop experiment sites that monitor drainage water, increased nitrate-nitrogen annual loads in streams are observed during lower yielding years (Malone and Ma, In Press, 2008). Podestá et al. (1999) have found high yielding years to be associated with warm ENSO events and low yielding years with cold ENSO events. The warm or cold ENSO events repeat on about a 2 year cycle. Knowing some of these cycles is of current interest to research in sustainable agriculture because it could potentially improve farm management practices. For example with appropriate variety selection and fertilizer application in a given year, profitable crop yields could be achieved with minimal nitrogen and other fertilizer components running off into streams or lakes.

Also a basic understanding of underlying associated environment processes is at hand. On a smaller time scale, oscillations on the order of several minute scales may be indicative of what are called "eddy cycles" which are possibly the main features of interest in analyzing this vector wind speed data over sub-daily periods. The wind speed observations and related variables collected simultaneously are needed to understand daily, seasonal, and longer term evaporation and other fluxes (like carbon dioxide) and related mass balances in current and alternative farming practices (Prueger et al., 2004).

With the goal of demonstrating a common approach, this paper presents the initial results from three completely different ongoing studies. While the problems are from different disciplines, they have analyses objectives in common: the identification of trends or large time scale behavior; the identification of intermediate scale cycles; and, if need be, the assessment and handling of comparatively shorter time scale variability.

\section{DATA AND METHODOLOGY}

\subsection{Data}

Series 1 is the 66 year-long Wisconsin state average annual corn crop yield $\left(\mathrm{Bu} \mathrm{Ac}^{-1}\right)$ record from 1940 to 2005. These crop survey data are available from the USDA National Agricultural Statistics Service (http://www.nass.usda.gov/) whose mission is to provide useful, accurate, and timely, statistics in service to U.S. agriculture. Users of the data include scientists, the business community, and policy analysts. Available data include state wide and county level yield data for major crops. For this analysis, time is cast as observation number in the sequence, here year 1939. 
Series 2 is a four year-long daily stream flow $\left(\mathrm{m}^{3} \mathrm{~d}^{-1}\right)$ record on the log scale starting from 2002 and continuing on through 2005. The data are from gage 350 on Beaver Creek in Iowa which is one monitoring site in the Iowa Conservation Effects Assessment Program (CEAP, USDA-ARS, 2004). A major goal of the program is to quantify the benefits of conservation practices. Stream flow and water quality measurements are among the watershed data being regularly monitored and recorded. Here, time is initially cast as day in the sequence with day 1 starting on January 1, 2002.

Series 3 is a half-hour long wind speed $\left(\mathrm{m} \mathrm{s}^{-1}\right)$ record sampled at 10 hertz with a 3-D sonic anemometer during a summer day in 2002 near Ames, IA. These observations were collected as one part of the multi-disciplinary Soil Moisture-Atmospheric Coupling Experiment or SMACEX for short (Kustas et al., 2005). Time is, again, initially cast as observation in the sequence so that observation 1 is the $0.1 \mathrm{~s}$ record for 18,000 data points ( $1 / 2$ hour).

\subsection{Methods}

\subsubsection{Trend Analysis}

Each series is examined for trend based on multiple tests. Included are graphs of the original series and the series from first differences. The first difference is a common method for removing trend and is known as a high pass filter (p. 19 in Chatfield, 2004). Also considered are the rank correlation coefficient and the Mann-Kendall's $\tau_{b}$. Finally spectra are examined for low frequency values for the original series and contrasted with spectra for the high pass filtered series.

\subsubsection{Spectral Analysis}

Discrete Fourier analysis is used for each series to calculate and examine spectra. In this study PROC SPECTRA from SAS ${ }^{\circledR}$ v. 9.1 is employed (SAS Inst., Cary, NC [The mention of a trade name is for informational purposes only and does not imply an endorsement by the USDAARS]); it uses the Tukey-Cooley FFT algorithm. Output options for the procedure include the number of spectral terms $(\mathrm{m})$, wave number $(\mathrm{k})$, the Fourier sine and cosine coefficients $\left(\mathrm{a}_{\mathrm{k}}^{2}\right.$ and $\mathrm{b}_{\mathrm{k}}^{2}$ ), spectral density ( $\left.\mathrm{S}_{-} 01\right)$, and periodgram values ( $\left.\mathrm{P}_{-} 01\right)$. Given the number of observations $(\mathrm{N})$, then $\mathrm{m}=1 / 2 \mathrm{~N}$ if $\mathrm{N}$ is even and $1 / 2(\mathrm{~N}-1)$ if $\mathrm{N}$ is odd. Spectral values are examined both formally and graphically via a $\mathrm{SAS}^{\circledR}$ macro (Meek, 2007). For each frequency ( $v$ ) or $\mathrm{k}$, a spectral density term $F$ test (p. 282 in Fuller, 1976), a variance relative amplitude $\left(R_{k}^{2}\right.$, p. 127 in Chatfield, 2004), and normalized cumulative periodgram $\left(\mathrm{C}_{\mathrm{k}}\right.$, p. 285 in Fuller, 1976) are calculated. Each of these calculations is relatively straight forward. Of course prior to running the tests on the output data set from PROC SPECTRA, N and the periodgram sum of squares $\left(\mathrm{P}_{\mathrm{s}}^{2}\right)$ are determined beforehand. Here $\mathrm{P}_{\mathrm{s}}^{2}$ is

$$
\mathrm{P}_{\mathrm{s}}^{2}=\sum_{\mathrm{i}=1}^{\mathrm{m}} \mathrm{P}_{-} 01(\mathrm{i}) .
$$

With $\mathrm{P}_{\mathrm{s}}^{2}$ available, the calculation for $\mathrm{F}$ test simplifies to 


$$
\mathrm{F}_{2,2 \mathrm{~m}-2}=(\mathrm{m}-1) \mathrm{P} \_01(\mathrm{k}) /\left(\mathrm{P}_{\mathrm{s}}^{2}-\mathrm{P} \_01(\mathrm{k})\right) \text { for } \mathrm{k}>0 \text {. }
$$

Note that when $N$ is even and $k=m=N / 2$, the last term's degree of freedom change because $b_{m}=0$. The term coefficient of determination, $\mathrm{R}_{\mathrm{k}}^{2}$, is

$$
\mathrm{R}_{\mathrm{k}}^{2}=\mathrm{P}_{-} 01(\mathrm{k}) / \mathrm{P}_{\mathrm{s}}^{2} \text {. }
$$

Similarly $\mathrm{C}_{\mathrm{k}}$, an associated cumulative form of $\mathrm{R}_{\mathrm{k}}^{2}$, is

$$
\mathrm{C}_{\mathrm{k}}=\sum_{\mathrm{i}=1}^{\mathrm{k}} \mathrm{P}_{-} 01(\mathrm{i}) / \mathrm{P}_{\mathrm{s}}^{2} \text {. }
$$

Spectral plots examined include the spectral density (S_01), the relative amplitude $\left(\mathrm{R}_{\mathrm{k}}^{2}\right)$, and the normalized cumulative periodgram $\left(\mathrm{C}_{\mathrm{k}}\right)$ with; $\mathrm{C}_{\mathrm{k}}$ labeled "Nrm Cum Prdgm" in the graphs. In these spectral graphs, the black dots are the $\mathrm{S} \_01$ in panels A (versus v) and B (versus k); the solid black line in both is the corresponding a Hanning weight interpolation (p. 133 in Chatfield, 2004). In panel $B$, the gray bar needles are the $R_{k}^{2}$ are references on the left hand gray vertical axis. Panel $C$ is $C_{k}$ vs $k$. In panels $A$ and $C$ the solid gray lines are $5 \%$ and $95 \%$ confidence limits (for the bounds in Panel A, see p. 296 in Fuller, 1976; for the bounds in Panel C see p. 287 also in Fuller). For each series, the spectra from the transform of original series, as is or raw, are examined first. Next the spectra from the transform of the first difference series (a high-pass filtered or detrended) are then examined.

\subsubsection{Time Series Modeling}

In signal processing and some other applications of the discrete Fourier transform, modeling and analysis is achieved by selecting the spectral terms of interest, i.e., the signal, and back transforming only the selected frequency terms. Recall that, ideally, the noise or insignificant terms are eliminated this way because inclusion of all the terms exactly interpolates the original data. Back transforming is generally done only on stationary series. The back-transformed values are thus smoothed (i.e., fitted). Rather than back transform selected spectral terms to model a given series, a general time series approach is used that is guided by the original spectral analysis and common diagnostics with further spectral analysis on model residuals. Ideally the models can have a trend with superimposed cycles and a possible autoregressive error structure, i.e., $y=$ Trend + Cycles $+A R$. This approach opens the door to a less restrictive and perhaps more insightful overall model than back transforming. Moreover, using a back transform of selected terms can be problematic because the trend is modeled as a superposition of low frequency terms and the resulting error structure may not be i.i.d. normal. Multiple performance criteria are considered including the regression standard error, $\mathrm{R}^{2}, \mathrm{R}_{\mathrm{PRESS}}^{2}$, log-likelihood, graph of the fit, and residual analyses. Here $\mathrm{R}^{2}=1$ - error sum of squares/corrected total sum of squares. For reasons unique to each series, all these series have outliers so final estimates employ a robust weight, here the Fair function (Table 1 in Heiberger and Becker, 1992). Formally, the Fair weight is

$$
\mathrm{w}(\mathrm{t})=1 /(1+|\mathrm{d}(\mathrm{t}) / \mathrm{c}|)^{2},
$$


where $\mathrm{t}$ is time in the model, $\mathrm{d}(\mathrm{t})$ is the standardized residual, and $\mathrm{c}$ is a constant set at 1.41 . When the robust estimation is used, weighted sum of squares terms replaced unweighted terms in the $\mathrm{R}^{2}$ definition.

\section{RESULTS AND DISCUSSION}

\subsection{Trend Tests}

For brevity the original and first difference time series plots are not shown. Trends are quite obvious in Series 1 and 3. In each case the first difference time series plots are noticeably different from that of the original series. All test statistic values are significant (Table 1). In all cases the spectra for the first difference series are completely different from those of the original. Relevant details and graphs are included in the sections that follow. Hence, none of these series could reasonably be considered stationary.

\subsection{Series 1}

Final analysis and results are for the raw data. The panels in Fig. 1 show the spectra for the raw data series. Consistent with the previously mentioned formal trend tests, these panel graphs show the series is not reasonably stationary. There is a negative relationship in panels A and B and the lowest four frequencies [or wave numbers] are an order of magnitude larger in spectral density than all of the other terms. At $\mathrm{k}=1$, the fundamental, $\mathrm{R}_{1}^{2}=0.51$. In panel $\mathrm{C}$, the normalized cumulative periodgram exceeds the confidence band starting at $\mathrm{k}=1$. In contrast, a positive relationship is shown in panels $\mathrm{A}$ and $\mathrm{B}$ of Fig. 2. Panel $\mathrm{C}$ indicates some of the frequencies are reasonably significant. Notices the largest two spectra are at $\mathrm{k}=26(2.3 \mathrm{y})$ and $\mathrm{k}=28(2.5 \mathrm{y})$. These two cycles may be related to known climate oscillations. Possible aliases for these cycles are also apparent.

A simple linear trend model is developed first, then the highest frequency term is added followed by the next highest. Nonlinear regression procedures are used with the amplitude, period, and phase angles being fit with starting values taken from the second spectral analysis. Except for drought and flood year outliers, diagnostics are reasonable. Residual autocorrelation is very slight. To reduce the influence of outliers, the model parameters and confidence limits are then re-estimated via the stated robust procedure. A graph is shown in Fig. 3; the model is

$$
\mathrm{Y}=38.18+1.558 \mathrm{t}-3.039(\sin (2 \pi(\mathrm{t}-0.6677) / 2.332)+\sin (2 \pi(\mathrm{t}+0.8584) / 2.540))
$$

This regression has $\mathrm{R}^{2}=0.968$. All parameters are significant $(\mathrm{p} \leq 0.01)$. The linear trend accounts for most of the variability and is mainly due to improvements in corn varieties. The overall pattern observed in this series has been found in many other yield series from both large and small areas that represent the crops grown throughout the Midwest and other parts of the world.

There are some matters to be considered in further research. Can corn and other crop yield variations be matched not just to the climate index for the ENSO but also to indices for the QBO, 
the NAO, and perhaps some others? Do the effects on crops of all these different cycles interact? Do drainage and stream nitrate-nitrogen loads exhibit related temporal patterns as yield with respect to the cycles? Finally, from a practical perspective, are the differences in yield and fertilizer use large enough to promote change in management practices?

\subsection{Series 2}

The spectra for the raw series are relatively large for the lowest $10 \mathrm{k}$ values (graph not shown). Relatedly, the spectra from the first difference series show a flat pattern with respect to $\mathrm{k}$ or $v$ (again, graph not shown). Furthermore all high frequency contributions and serial correlation are matters not of any immediate research interest. Given all these considerations, series 2 data are, hence, aggregated to the average daily value for the week. The resulting series has 208 weekly values; their spectra are shown in Fig. 4. Although the formal trend tests show significance (Table 1), the annual cycle is obviously the dominant phenomenon in this series. It is, therefore, modeled first. Next the trend is modeled as splined polynomials in $\sqrt{\mathrm{t}}$. In turn the 26 week harmonic is added following the longer period cycle and a distant harmonic of it. An AR1 error term competes the modeling process. The initial goal of this analysis is to determine climatic behavior. So some rainfall driven short-term large flow events occur in the series; hence, the use of the robust method for the final estimate. A graph of the final model is shown in Fig. 5. The components of the $y=$ Trend + Cycles + AR model are as follows:

$$
\begin{gathered}
\text { Trend }=\left\langle\begin{array}{ll}
11.000-0.1208 \sqrt{t}, & t \leq 108.2 \\
9.748+0.2197(t-108.2)^{1 / 2}-0.0189(t-108.2), & t>108.2
\end{array}\right\rangle, \\
\text { Cycles }=\left\langle\begin{array}{l}
1.177 \sin (2 \pi(\mathrm{t}-8.922) / 51.34)-0.565 \sin (4 \pi(\mathrm{t}-3.544) / 51.34) \\
+0.252(\sin (2 \pi(\mathrm{t}+1.646) / 35.44)-\sin (6 \pi(\mathrm{t}-1) / 35.44))
\end{array}\right\rangle, \\
\text { and AR }=0.525 \epsilon_{\mathrm{t}-1}+\mathrm{e}_{\mathrm{t}} .
\end{gathered}
$$

This regression has $\mathrm{R}^{2}=0.934$. All parameters are significant $(\mathrm{p} \leq 0.01)$. The yearly cycle is the largest single variability component. An annual cycle is common to many hydrological processes. Cycles 2 and 4 are harmonics of 1 and 3. The AR1 error structure is probably not of any immediate interest and suggests considering further aggregation. In some hydrological series, however, a particular high frequency term could be of considerable interest.

As previously stated, this work is a preliminary analysis intended to identify large scale behavior in this kind of data. Further work may follow along two paths. With longer flow records analysis could lead to assessing if influence from any of the previously listed natural cycles can be identified along with some other possible geophysical factors. With concurrent weather observations, some of the extremes in due to storm or other event variability could be modeled. In addition, direct analysis of stream flow record could benefit by better assessment of the non-normality for such series. 


\subsection{Series 3}

As in Series 2, high frequency terms are once again small and not of primary interest, so the data were averaged over a $30 \mathrm{~s}$ interval and the resulting series has 60 observations. The time variable is scaled to minutes so observation 1 is $0.5 \mathrm{~min}$ and observation 60 is $30.0 \mathrm{~min}$. Based on the trend tests and the spectra shown in Fig. 6 for the 0.5 min data, Series 3 is also clearly not stationary. Conceptually this series could be considered the superposition of low frequency damped and comparatively undamped higher frequency oscillations; hence, fractional order Bessel functions (Antosiewicz, 1970) are considered to model the trend. At first a simple $\mathrm{J}_{0}$ term is tried, where $J_{0}(z)=\sin (z) / z$. Surprisingly, the result gives $R^{2}=0.495$. Various other single terms were tried including $\mathrm{Y}_{0}(\mathrm{z}), \mathrm{J}_{1}(\mathrm{z}), \mathrm{Y}_{1}(\mathrm{z}), \mathrm{J}_{2}(\mathrm{z})$, and $\mathrm{Y}_{2}(\mathrm{z})$. Out of the latter the only reasonable alternative is with a $\mathrm{J}_{2}(\mathrm{z})$ term but it only results in about $1 \%$ improvement and so is not used because of the additional complexity of the form. Next, regular trigonometric terms are added, one at a time, followed by an AR error. There may be short term wind gusts influences which initially are not to be considered; hence, the robust procedure is then used. The final model is shown in Fig. 7. The components of the $y=$ Trend + Cycles + AR model are as follows:

$$
\begin{gathered}
\text { Trend }=2.420-3.024 \mathrm{~J}_{0}(2 \pi(\mathrm{t}-5.88) / 10.51) \\
\text { Cycles }=\left\langle\begin{array}{c}
-1.008 \sin (2 \pi(\mathrm{t}-9.12) / 6.63)+0.336 \sin (4 \pi(\mathrm{t}-3.52) / 6.63) \\
+0.646 \sin (6 \pi(\mathrm{t}-0) / 6.63))
\end{array}\right. \\
\mathrm{AR}=0.4316 \epsilon_{\mathrm{t}-1}+\mathrm{e}_{\mathrm{t}}
\end{gathered}
$$

The regression has $\mathrm{R}^{2}=0.881$. All parameters are significant $(\mathrm{p} \leq 0.01)$. The $\mathrm{J}_{0}$ function has a longer period than that of the undamped cycles and the two higher frequency cycles are multiples of the first. Once more, the AR1 error structure is probably not of any immediate interest and suggests considering further aggregation. The caveat given for Series 2 is, again, extant: In some of wind speed series a particular high frequency term could be of great interest.

Oscillations on the order of several minute scales may be indicative of what are called "eddy cycles" which are possibly the main features of interest in analyzing this kind of data over subdaily periods. Other trend forms, basis functions, and smaller scale cycles may be considered in further work along with the applicability of these results to other related fluxes.

\section{SUMMARY AND CONCLUSIONS}

All series have a trend and cycles of interest. The corn yield series has a simple linear trend and two cycles with the same periods as known quasi-biennial climate oscillations. The model for stream flow has a complicated trend form consisting of splined polynomials in the square root of time. Cycles include one with an expected approximate yearly period and others of about 8,6 , and 3 month periods. Also an AR1 error structure is added. A zero order fractional Bessel function models the trend as a damped oscillation with a period of $10.5 \mathrm{~min}$. Smaller scale undamped cycles of 6.6,3.3 and 2.2 min are added along with an AR1 error structure. All of these oscillations may characterize the "eddy" cycles of interest. The serially correlated error structures in the last two series may reflect smaller scale variability not of primary concern. 
The use of time series methods instead of the inverse transform on selected frequencies allows for simultaneous estimation of all components. Moreover, it opens the door to the use of a much broader class of functions to model the trend, to the use of other kinds of periodic functions to model the cycles, and to the incorporation of dependence structure in the error term. This approach may provide useful insightful as well. In addition it offers a framework for several different ongoing and some future research programs at the National Soil Tilth Laboratory.

\section{ACKNOWLEDGEMENTS}

Thanks to Ms. D. Palmquist, USDA-ARS, Peoria, IL, Ms. J. Fleming, USDA-ARS, Ames, IA, and one anonymous reviewer for comments. This work was supported by the USDA-ARS National Soil Tilth Laboratory, Ames, IA, Dr. J.L. Hatfield, Director.

\section{REFERENCES}

Antosiewicz, H.A. 1970. Ch. 10, Bessel functions of fractional order. In: M. Abramowitz and I. Stegun (Eds.), Handbook of mathematical functions with formulas, graphs, and mathematical tables, $9^{\text {th }}$ Printing. Dover Pubs., New York, NY. 1046 pp.

Chatfield, C., 2004. The analysis of time series, an introduction, $6^{\text {th }}$ ed. Chapman\&Hall/CRC Press, Boca Raton, FL. 333 pp.

Fuller, W. 1976. An introduction to statistical time series. J. Wiley and Sons. New York, NY. $470 \mathrm{pp}$.

Heiberger R.M. and R.A. Becker. 1992. Design of an S function for robust regression using iteratively reweighted least squares. J. Comp. Stat. Graph. 1(3): 181-196.

Kustas, W.P., J.L. Hatfield, and J.H. Pruegar. 2005. The soil moisture-atmosphere coupling experiment (SMACEX): Background, hydrolometeorological conditions, and preliminary findings. J. Hydrolomet. 6: 791-806.

Malone, R.W. and L. Ma. (In Press, 2008). N uptake affects corn yield and N loss in tile drains as simulated by the Root Zone Water Quality Model (RZWQM). In: L. Ma, T. Bruulsema, and L. Ahuja, (eds.), New Advances in Understanding and Quantification of Plant N Uptake CRC Press, Boca Raton, FL.

Meek, D. 2007. A Macro for producing graphs used in assessing a spectrum, Paper D2. In: A. Katschke, Ed., Data Visualization and Graphics Section, MidWest SAS ${ }^{\circledR}$ Users Group Annual Conference Proceedings, 28-30 Oct. 2007, Des Moines, IA. SAS ${ }^{\circledR}$ Inst. Inc., Cary, NC. 6 p.

Podestà, G.P., C.D. Messina, M.O. Grondona, and G.O. Margin. 1999. Associations between 
grain crop yields in Central-Eastern Argentina and the El Niño-Southern Oscillation. J. Appld. Meteor. 38: 1488-1498.

Prueger, J. H., and Coauthors, 2004: Tower and aircraft eddy covariance measurements of water, energy, and carbon dioxide fluxes during SMACEX. J. Hydrometeor 6: 954-960.

Tomer, M.D., D.W. Meek, D.B. Jaynes, and J.L. Hatfield. 2003. Evaluation of nitrate-nitrogen fluxes from a tile-drained watershed in Central Iowa. J. Environ. Qual. 32: 642-653.

Tomer, M.D., D.W. Meek, and L.A. Kramer. 2005. Agricultural practices influence flow regimes of headwater streams in Western Iowa. J. Environ. Qual. 34: 1547-1558.

USDA-ARS. 2004. ARS CEAP project plan. USDA-ARS, Beltsville, MD. 168 pp. (This document is available at: $\mathrm{ftp}: / / \mathrm{ftp}-\mathrm{fc} . \mathrm{sc}$. egov.usda.gov/NHQ/nri/ceap/arsceapprojectplan.pdf) 
Table 1. Trend Test Results.

\begin{tabular}{lrrrrr}
\hline & & \multicolumn{2}{c}{-- Spearman -- } & \multicolumn{2}{c}{----- Kendall ------ } \\
Data Set & \multicolumn{1}{c}{$\mathrm{n}^{*}$} & \multicolumn{1}{c}{$\mathrm{r}_{\mathrm{s}}^{\dagger}$} & \multicolumn{1}{c}{$\mathrm{p}_{\mathrm{r}}^{\ddagger}$} & \multicolumn{1}{c}{$\tau_{\mathrm{b}}{ }^{\S}$} & \multicolumn{1}{c}{$\mathrm{p}_{\tau}^{{ }^{\top}}$} \\
\hline Series-1 & 66 & 0.9453 & $<0.0001$ & 0.8250 & $<0.0001$ \\
Series-2 & 1461 & -0.0943 & 0.0003 & -0.0678 & $<0.0001$ \\
Series-3 & 18000 & -0.4971 & $<0.0001$ & -0.3285 & $<0.0001$ \\
\hline
\end{tabular}

${ }^{*} \mathrm{n}$ Number of observations

${ }^{\dagger} r_{s}$ Spearman's rank correlation coefficient

${ }^{\ddagger} \mathrm{p}_{\mathrm{r}}$ Alpha probability for $\mathrm{r}_{\mathrm{s}}$

${ }^{\S} \tau_{b}$ Kendall's Tau b sign test for independence

${ }^{\top} p_{\tau}$ Alpha probability for $\tau_{b}$ 


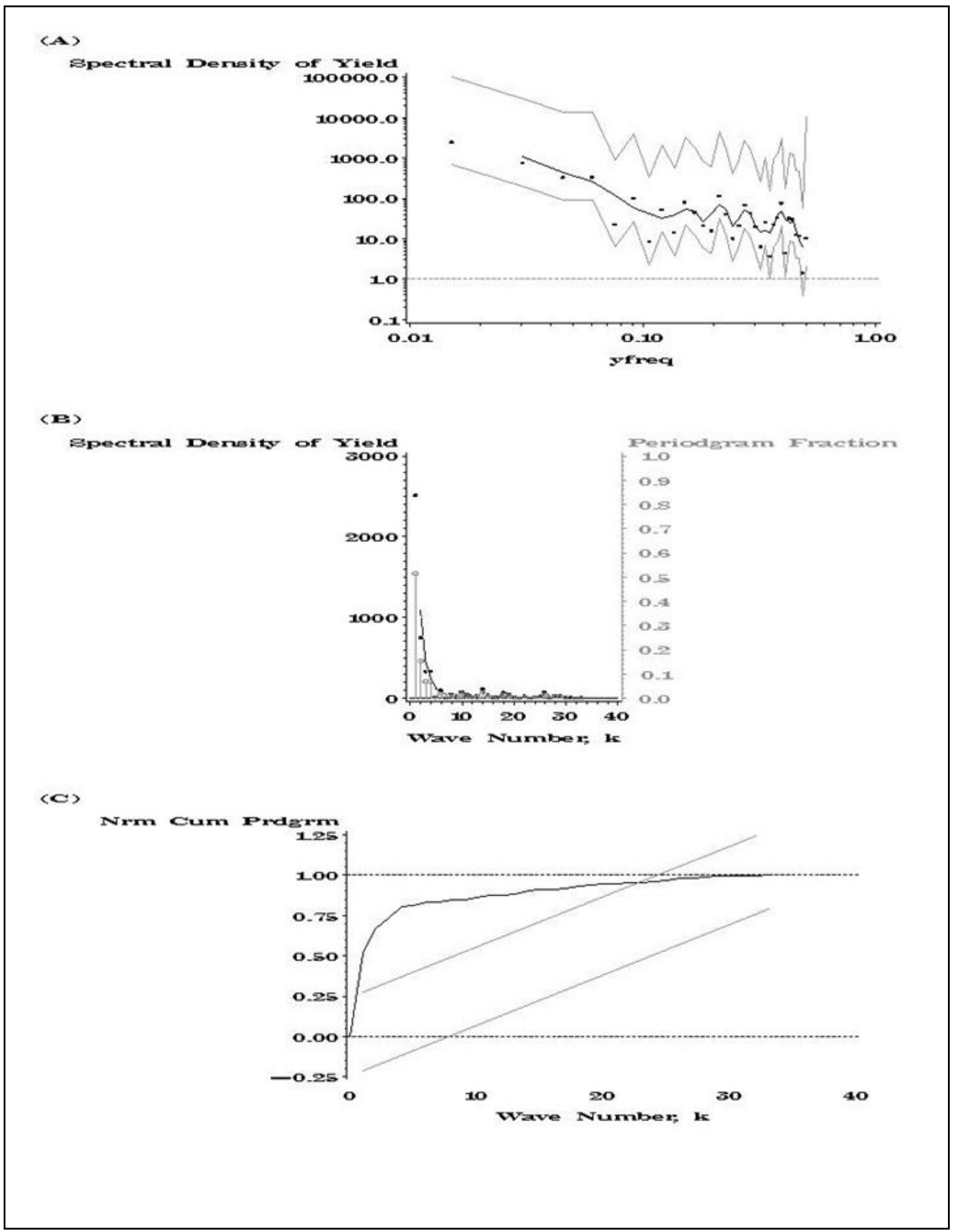

Figure 1. Panel graphs of the spectra for the raw yield series. Notice the multiple indications of trend. 


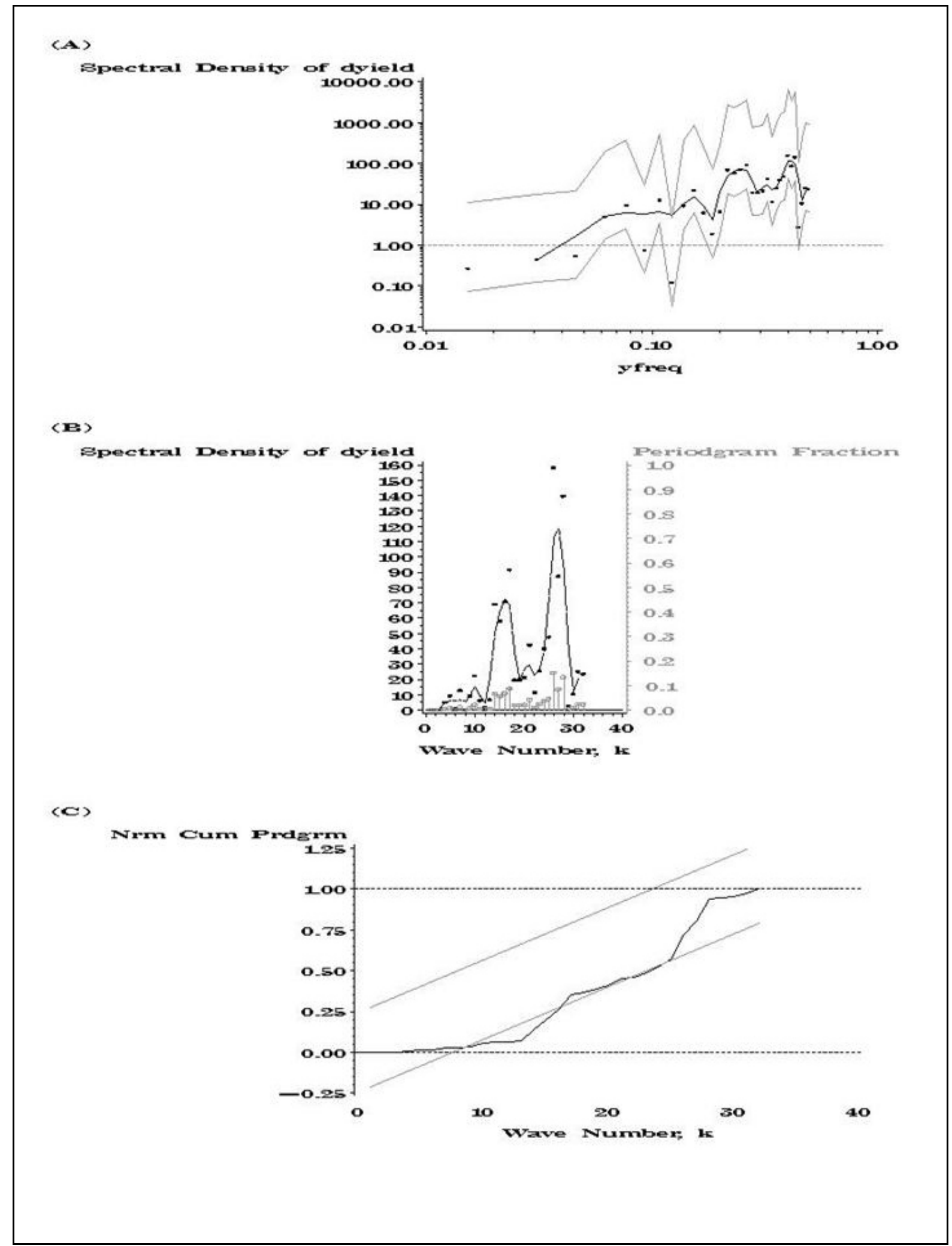

Figure 2. Panel graphs of the spectra for the first differenced of the yield series. 


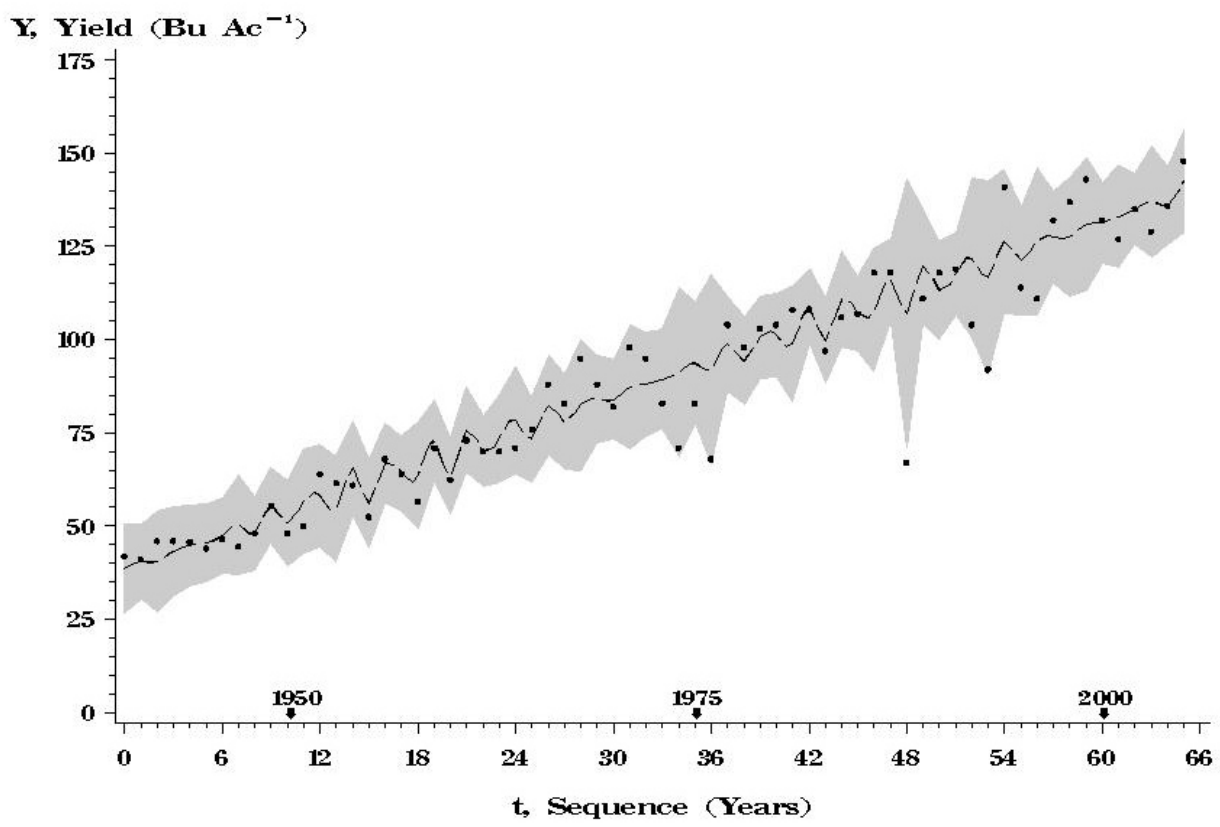

Figure 3. A graph of the selected yield model. The black dots are the observed yield, the solid black line is the regression model, and the gray band is the $95 \%$ prediction interval. The two most extreme outliers, 1988 and 1993, had growing seasons characterized by drought and flooding. 


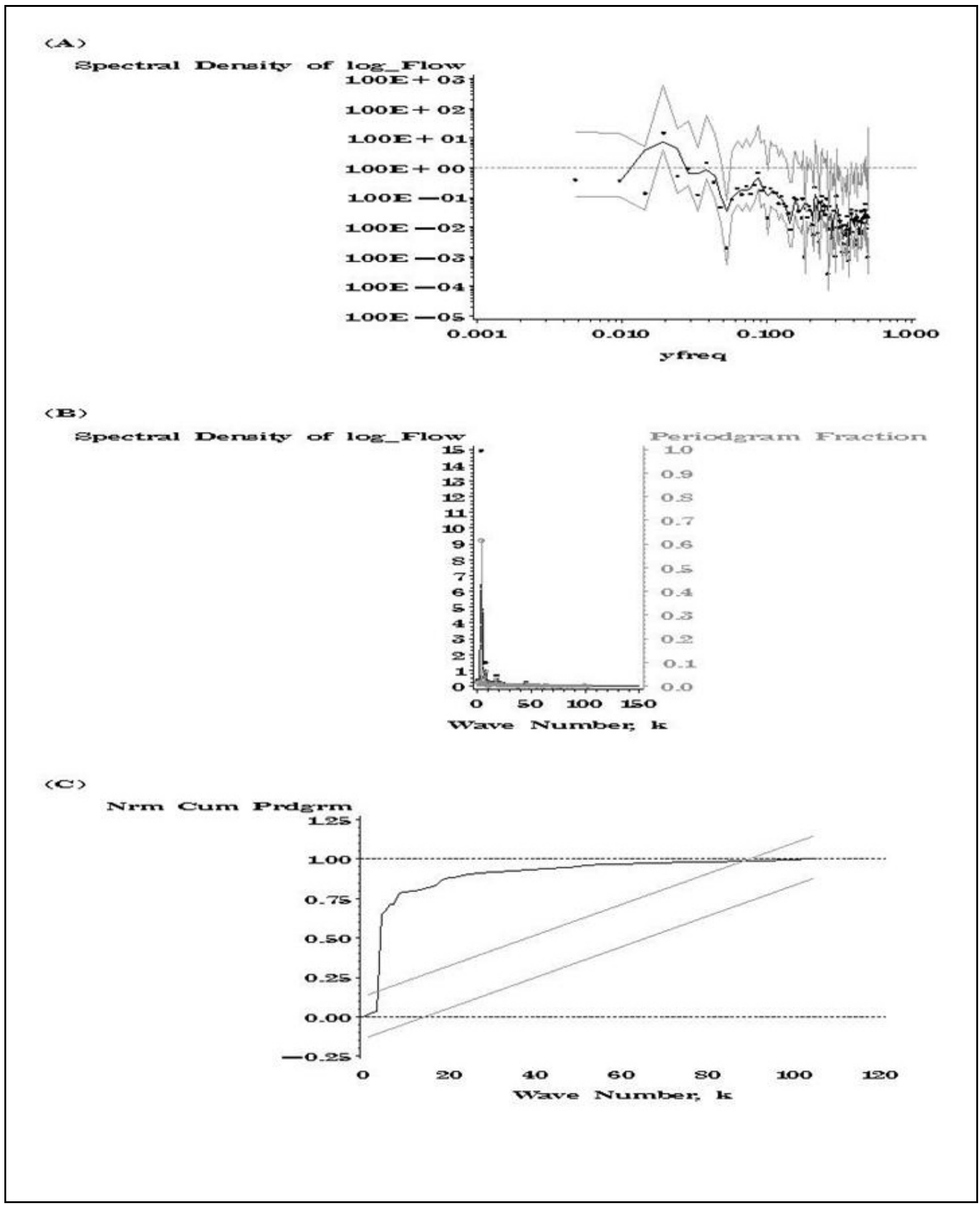

Figure 4. Graphs of the spectra for the $\log ($ flow) data. There is an overall negative relationship in panels $\mathrm{A}$ and $\mathrm{B}$ which suggests a trend. Notice in all panels the largest term is for $\mathrm{k}=4$ (period $=52$ weeks) with $\mathrm{R}_{4}^{2}=0.61$. The next largest is at $\mathrm{k}=8$ (period $=26$ weeks), a harmonic. Both of these terms are the only ones above the 1 line in panel A. 


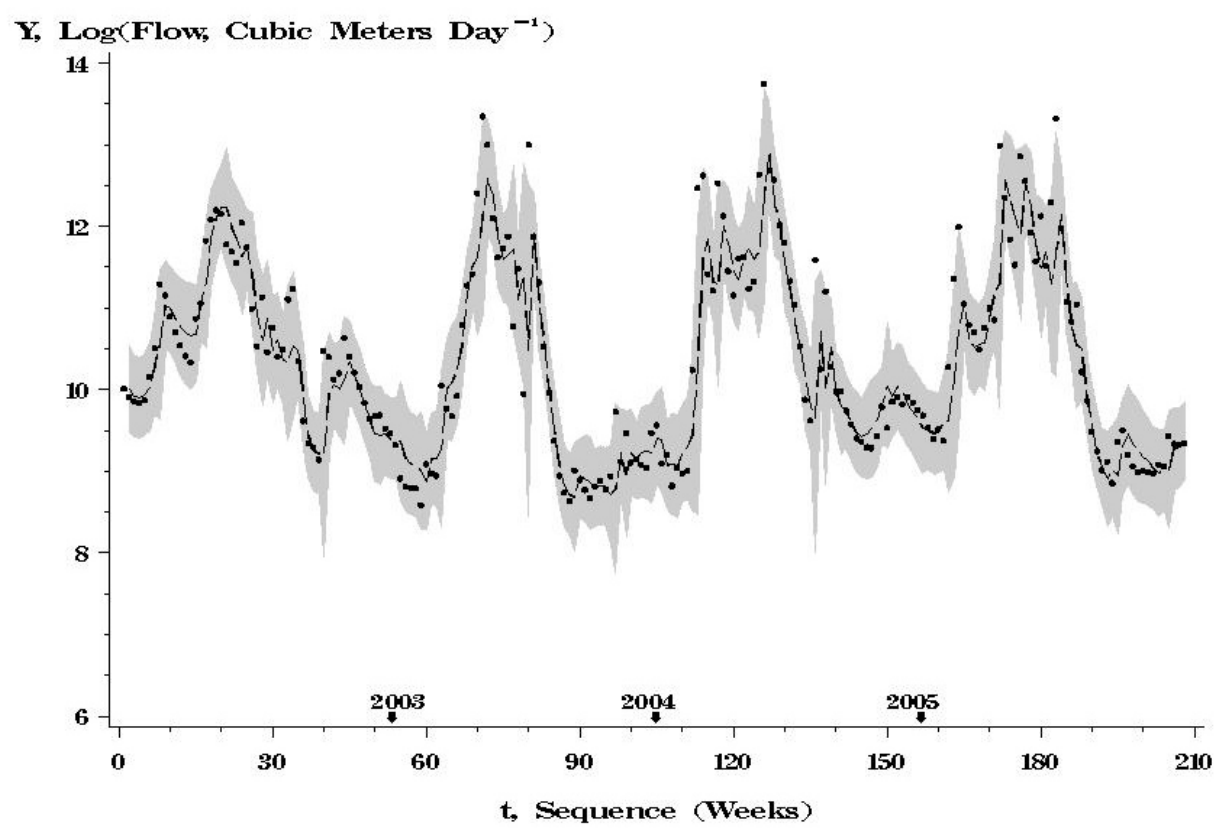

Figure 5. A graph of the selected log scale flow model. The black dots are the observations, the solid black line is the regression model, and the gray band is the $95 \%$ confidence interval for the predictions. 

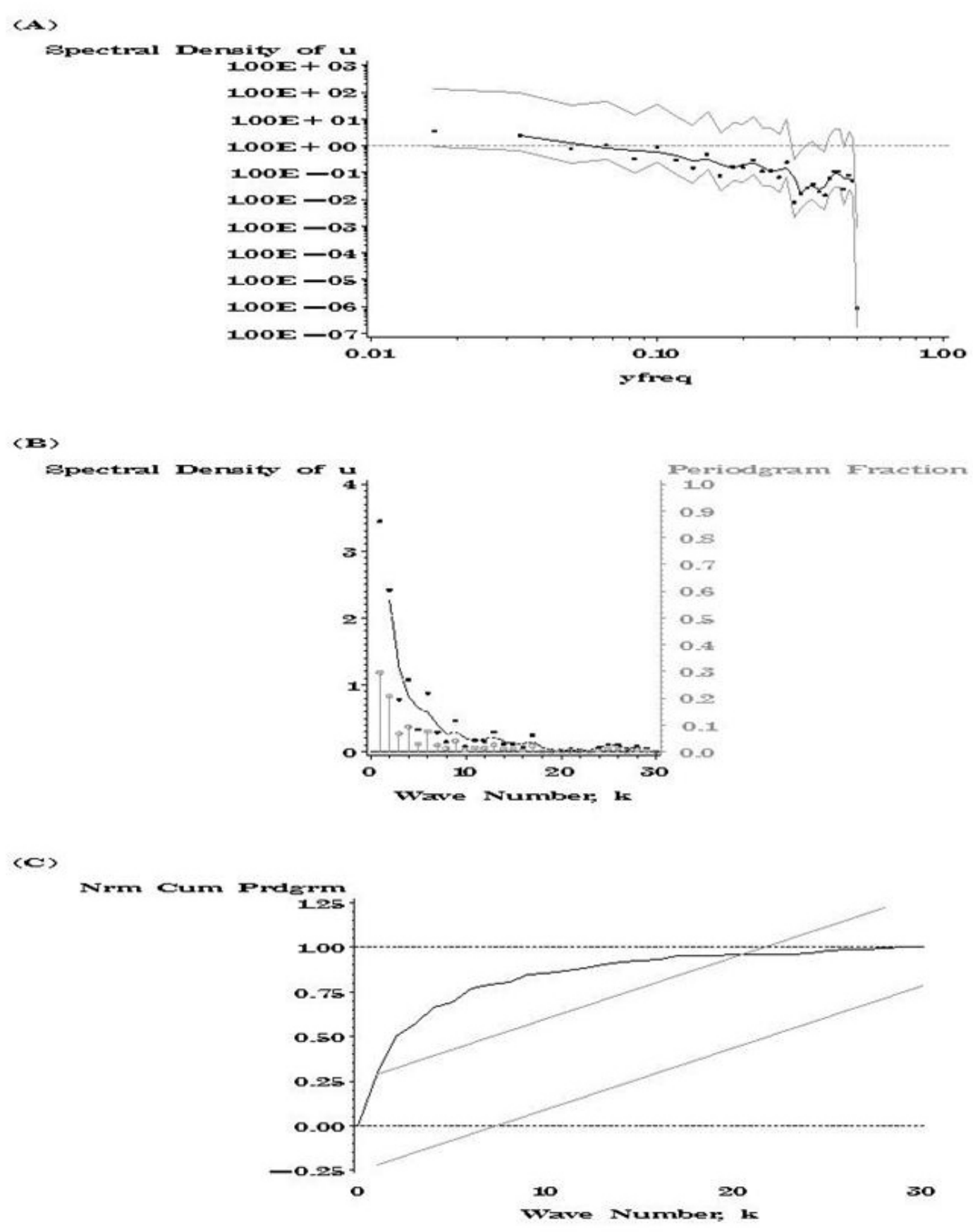

Figure 6. Graphs of the wind speed spectra. Panels A and B show a negative relationship of spectral density to frequency and wave number. All the terms in $1 \leq \mathrm{k} \leq 10$ are large with $\mathrm{R}_{1}^{2}=0.3$ and $\mathrm{R}_{2}^{2}=0.2$. In panel $\mathrm{C}$, the normalized cumulative periodgram exceeds the confidence band starting at $\mathrm{k}=1$. The pattern suggests the presence of considerable trend. 


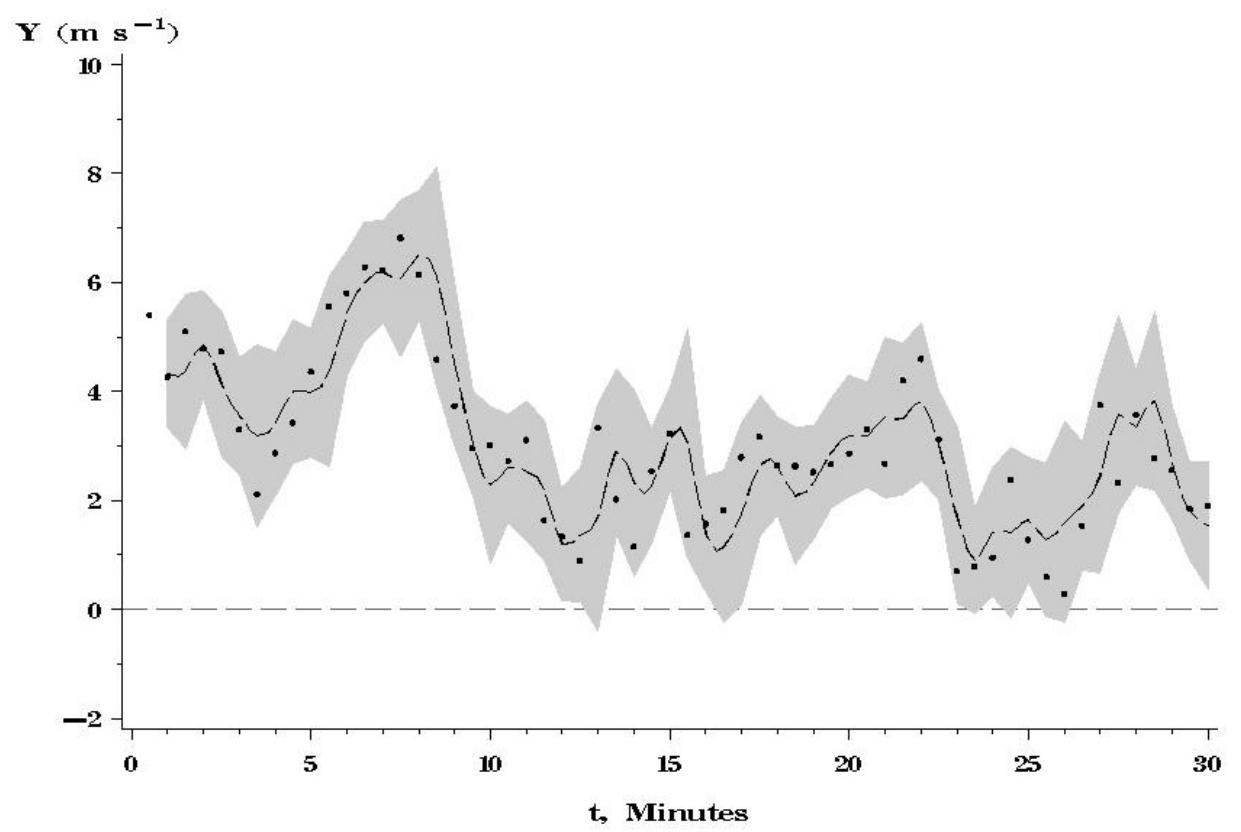

Figure 7. A graph of the selected wind speed model. The black dots are the observations, the solid black line is the regression model, and the gray band is the $95 \%$ confidence interval for the predictions. 